\title{
Evaluation of Immune Responses and Histopathological Effects against Gamma Irradiated Avian Influenza (Sub type H9N2) Vaccine on Broiler Chicken
}

\author{
Shadi Javan ${ }^{1}$ \\ https://orcid.org/0000-0001-7383-993X \\ Farahnaz Motamedi-Sedeh ${ }^{\star 2}$ \\ https:// orcid.org/0000-0003-3388-9670
}

Mehrouz Dezfoolian ${ }^{1}$

https://orcid.org/0000-0002-1003-2896

Viskam. Wijewardana ${ }^{3}$

https://orcid.org/0000-0002-5787-8792

\begin{abstract}
${ }^{1}$ Department of Microbiology, Karaj Branch, Islamic Azad University, Karaj, Alborz, Iran; ${ }^{2}$ Nuclear Science and Technology Research Institute, Nuclear Agriculture Research School, Veterinary and animal Science Department, Karaj, Alborz, Iran; ${ }^{3}$ International Atomic Energy Agency (IAEA), Joint FAO/IAEA Division of Nuclear Techniques in Food and Agriculture, Department of Nuclear Sciences and Applications, Animal Production and Health Laboratory, Vienna, Austria.
\end{abstract}

Received: 2020.02.17; Accepted: 2020.04.06.

*Correspondence: farah.motamedi@gmail.com; fmotamedi@aeoi.org.ir; Tel.: +98-26-34252322

HIGHLIGHTS

- Gamma Irradiated Avian Influenza (H9N2) Vaccine was prepared by 30 kGy irradiation.

- Broiler chickens were vaccinated by two routs; intranasal and subcutaneously.

- All the vaccinated chickens showed a significant increase in antibody titration.

- The most increasing of immune responses was in irradiated vaccine plus Trehalose.

Abstract: Vaccination is a good strategy for the prevention of avian influenza virus. In this research Gamma Irradiated Avian Influenza (Sub type H9N2) Vaccine (GAIV) was prepared by 30 kGy irradiation and used for vaccination of broiler chickens. The purpose was a comparison of immune responses in the two routes of administration for the GAIV vaccine; intranasal and subcutaneously, use of Montanide ISA70 and Trehalose accompanied with irradiated vaccine and compare with formalin vaccine. The Influenza Virus A/Chicken/IRN/Ghazvin/2001/H9N2 was irradiated and used for vaccine formulation, and formalin inactivated AIV was used as conventional vaccine. Chickens were vaccinated by GAIV with and without Trehalose, GAIV and formalin vaccines with ISA70, two routes of administration were intranasal and subcutaneously. All the vaccinated chickens showed a significant increase in antibody titration. The most significant increase of antibody titration was in irradiated vaccine plus Trehalose groups intranasal and subcutaneously. After the first and second intranasal vaccination, the amount of IFN-gamma increased in the irradiated vaccine plus Trehalose group compared to other groups. However, most of the vaccinated groups did not show any significant increase of IFN- $\alpha$ concentration. Histopathological examination revealed lymphocyte infiltration $(++)$, foci dispersed of hemorrhage and edema in intranasal vaccination groups and in addition to these, thickening of alveolar septa was observed in the injection groups. GAIV vaccine can be a good candidate for vaccine preparation, and Trehalose as a stabilizer protects viral antigenic proteins, also makes more absorbance of antigen by the inhalation route. In vaccinated chickens the ulcers in injected vaccines were lower than intranasal vaccines. 
Keywords: avian Influenza; gamma irradiation; vaccine; immune response; histopathology.

\section{INTRODUCTION}

Influenza virus is a member of Orthomyxoviridae family, it has 5 genera including: Influenza $A, B, C$, Thogotovirus, and Isavirus [1]. Avian influenza virus (AIV) related to genus influenza $A$ has segmented negative sense RNA, two surface glycoproteins HA and NA. There are 16 HA and 9 NA sub types [2,3].

The AIV is divided into two groups: low pathogenic avian influenza (LPAI) and high pathogenic avian influenza (HPAI). There is a possibility that LPAI mutate and changes to HPAI. The AIV sub type H9N2 distinguished as LPAI. Wild birds are the physical storage for the AIV and sometimes this virus transmits to domestic birds including hens, chickens, ducks, goose and swan [4-8]. LPAI can break species barrier and cause infection in pig, horse, and human [9]. Vaccination is a good policy for infectious diseases such as avian influenza virus because it reduces complications of AIV in bird [10,11]. The chemically inactivated influenza virus vaccines provide surface antigens or split product. These vaccines have low immunogenicity than live attenuated whole virus vaccine because surface antigens including HA and NA can be altered by chemical treatment thus immunological epitopes essential for vaccine efficacy are lost [12]. Alternatively, there are many methods for inactivation of influenza virus including heat treatment, ionizing radiation, UV irradiation and gamma irradiation [12].

Because of the antigenic variations in the influenza virus, designing a new vaccine that induces a broadly protective immune response is essential $[13,14]$. It is shown that gamma- irradiated influenza A virus $(\gamma$-Flu) as a vaccine is effective. It can induce $T$ cell responses and provides cross-protective immunity against seasonal and pandemic influenza virus [5,13]. The gamma-irradiation dose is very important because the level of structural damage of proteins is dose and temperature dependent [5].The gamma irradiation has higher penetration, little effect on the antigenic construction if used at the right dose and it breaks RNA strand of virus, therefore it is the perfect method for virus inactivation [13,14]. Consequently, there are two mechanisms of virus inactivation by gamma irradiation: direct and indirect. Direct virus inactivation by gamma irradiation is mainly caused by radiolytic cleavage or cross linking of genetic material. Indirect effects of gamma irradiation are caused by the action of radicals such as $\mathrm{OH}$, due to the radiolytic cleavage of water, and ozone which created from the radiolytic cleavage of $\mathrm{O}_{2}$. Viral nucleic acid and viral protein can react with these molecules. Stop of viral nucleic acid replication, via both direct and indirect effects, is the main mechanism of virus inactivation by gamma irradiation [15-19]. The specific aims of this study is to compare immune responses in two routes of the administration of gamma irradiated Avian Influenza sub type $\mathrm{H}_{9} \mathrm{~N}_{2}$ Vaccine (GAIV); intranasally and subcutaneously and the use of Trehalose and Montanide ISA70 accompanied with vaccine administration through prevention of virus shedding in vaccinated chicken after challenge.

\section{MATERIAL AND METHODS}

\section{Virus and Vaccines}

The virus used in our study was AIV sub type H9N2 strain, A/Chicken/IRN/Ghazvin/2001, obtained from the Razi Vaccine and Serum Research Institute of Iran. The optimum dose of gamma irradiated dose and inactivation of virus samples was carried out according to the procedure described by Salehi and coauthors [20]. Briefly; after multiplication of AIV on embryonated SPF (Specific Free Pathogen) chicken eggs, the allantoic fluids were tested using hemagglutination test for Hemagglutinin antigen (HA) titration [20] and virus titration via embryo infective dose (EID50) of infected allantoic fluid was calculated according to the Reed and Muench formula [21,23], Gamma ray dose $30 \mathrm{kGy}$ was recommended for the frozen virus samples [20]. The Nordian model 220 gamma cell instruments was used for irradiation of AIV in a dose rate of 2.07 Gy/s and activity of $8677 \mathrm{Ci}$ for virus inactivation. Gamma-irradiated AIV was stored as an irradiated vaccine plus $20 \%$ Trehalose $(1 \mathrm{M})$ (a disaccharide of glucose, as a protein protectant) under frozen conditions $\left(-70^{\circ} \mathrm{C}\right.$ ). Gamma irradiated AIV was used as irradiated vaccine. Formalin vaccine was prepared according to Razi protocol, briefly; a formalin concentration of $0.1 \%$ at $25^{\circ} \mathrm{C}$ inactivated the virus for $24 \mathrm{~h}$ and used as formalinvaccine [23]. In addition we used Montanide ISA 70 as an adjuvants along with irradiated vaccine and formalin vaccine. Injectable vaccine and stable Water-in-oil (W/O) emulsions were obtained by mixing Montanide ISA70 and antigenic media (H9N2) under a high shear rate. Then, $20 \%$ of Trehalose $(1 \mathrm{M})$ was added to irradiate inactivated AIV. The vaccine groups were according to table 1: sterile PBS (IN), Irradiated AIV (the two routes of administration; intranasal (IN) and subcutaneous (SC)), irradiated AIV with Trehalose (the two 
routes of administration; intranasal and subcutaneous), formalin AIV (IN), formalin AIV with ISA70 (SC), irradiated AIV with ISA 70 (SC).

\section{Chicken Experiment}

A total of 160 one day-old broiler chicks (Ross 308) were purchased from the Hen \& Chicken of Alborz Company (Iran), individually weighed and randomly distributed for treatments. The Light was provided continuously for the first three days post hatch, after that 23 hours light and 1 hour dark (23L:1D) was provided. At one day of age, the room temperature was set at $33^{\circ} \mathrm{C}$ and subsequently reduced by $2^{\circ} \mathrm{C} /$ week. Birds had free access to water and feed a corn-soybean meal-based diet. Diets were fed during the 3-phase feeding schedule: starter (0 to $14 \mathrm{~d}$ ), grower (14-22 d), and finisher (24-48 d). All diets were mashed and formulated to meet or exceed the minimum requirements for broiler chickens according to Ross 308 catalogue (2014) [22]. The chickens were divided into 16 groups, one group was negative control, and 8 groups received one dose of vaccine at 11 days age, and sampling was done two weeks after the first vaccination. The other 8 groups received two doses of vaccines at 11 days (prime) and at 25 days (booster) and sampling was done two weeks after the second vaccination. The route of administration was either intranasal (IN); drop on the nose or injection; subcutaneously (SC) in the back of the neck. The negative control and vaccinated groups were housed at the same condition in two separate places. The chickens in all of the groups were weighed, bled and humanely sacrificed and necropsy of the lung was performed for histopathological studies. The blood samples were used for neutralizing antibody titration via the hemagglutination inhibition (HI) test [23].

\section{Specific Neutralizing Antibody Response by HI test}

Briefly, the chicken sera were serially twofold diluted with sterile PBS in 96-well Microplates. The diluted sera were mixed with 4 hemagglutinin units of virus antigen (the infected allantoic fluids) and incubated at room temperature for $30 \mathrm{~min}$. Chicken red blood cells (1\%) were added to the antigen-serum dilution mixtures and incubate at room temperature for $30 \mathrm{~min}$. The $\mathrm{HI}$ titers are expressed as reciprocals of the highest serum dilutions that showed complete hemagglutination inhibition $(\mathrm{HI})$.

\section{Cytokine assay and Spleen Lymphocyte Proliferation Response}

The spleens of the vaccinated chicken were removed aseptically two weeks after the first vaccination and two weeks after boost immunization. The single splenic lymphocyte suspensions were prepared and incubated in 96-well plates at 105 cells/well by RPMI 1640 plus $10 \%$ fetal calf serum at $37^{\circ}$ in $5 \%$ CO2. The cells were stimulated with $3 \mu \mathrm{L}$ of irradiated inactivated AIV (with EID50 equal $108 / \mathrm{mL}$ ) in triplicates. At $48 \mathrm{~h}$ post stimulation, supernatants of splenic cells were collected to assess interferon (IFN-gamma and IFNalpha) production using a chicken IFNa Biotek. Inc ELISA (Cat No: DIY0908c-003) and chicken IFNy-Cytoset ELISA kit, Invitrogen (Cat No: CAC1233) following manufacturer's instructions [20,23]. Also the spleen lymphocyte proliferation assay was carried out with Cell Proliferation ELISA, BrdU kit (colorimetric) Roche Cat. No. 11647229001 according to the manufacturer's instruction. Briefly; BrdU labeling reagent was diluted 1:100, added $10 \mu \mathrm{L} /$ well and incubated the cells $2-24 \mathrm{~h}$ at $37^{\circ} \mathrm{C}$. Labeling medium was removed by tapping off, added $200 \mu \mathrm{L} /$ well FixDenat to the cells and after $30 \mathrm{~min}$ at $25^{\circ} \mathrm{C}$, then $100 \mu \mathrm{L} /$ well anti-BrdU-POD working solution was added and incubated $90 \mathrm{~min}$ at $25^{\circ} \mathrm{C}$. The conjugated antibody was removed by flicking off and washed wells with $200 \mu \mathrm{L} /$ well washing solution 3 times. $100 \mu \mathrm{L} /$ well substrate solution was added, incubated at $25^{\circ} \mathrm{C}$ until color development (30 min), then stop solution was added ( $25 \mu \mathrm{L} /$ well $\left.1 \mathrm{M} \mathrm{H} 2 \mathrm{SO} 4\right)$. The absorbance was measured with an ELISA reader at $450 \mathrm{~nm}$. SI was calculated for each sample (Stimulating Index= Mean of OD for stimulated well/ Mean of OD un-stimulated well).

\section{Histopathology examination}

The lung samples of vaccinated chicken were collected for histopathology studies at 2 weeks after the first vaccination and two weeks after the second vaccination [24,25]. The tissues were fixed in formalin solution $10 \%$, embedded in paraffin and cut in to $4 \mu \mathrm{m}$ thick sections and fixed on slides. With the staining were done by H\&E (hematoxylin and eosin) method. The prepared slides were evaluated by a qualified veterinary pathologist [26-28].

\section{Statistical analysis}

The analysis of variance (oneway ANOVA) followed by Duncan's multiple range test was used for statistical analysis. Differences were considered to be statistically significant when $p<0.05$. 


\section{RESULTS}

\section{Virus titration and neutralizing antibody responses}

The virus titration for the vaccine was $108.5 / \mathrm{mL}$ EID50 and hemagglutinin antigen assay for irradiated and non-irradiated avian influenza A sub type H9N2 virus samples were about 10 Log2. Thus the antigenicity of the HA antigen did not change in irradiated AIV. Also the safety test was done for irradiated AIV H9N2 (at $30 \mathrm{kGy}$ ) on SPF eggs and did not show any virus multiplication during four blind passages. These data provide information that virus inactivation was done completely. Neutralizing antibody responses were measured by the $\mathrm{HI}$ technique in serum samples of vaccinated chickens and reported in table 1 . According to statistical analysis, the most significant increase for antibody titration in IVT intranasal and subcutaneously at 2 weeks after the second vaccination, also in IVS and FVS groups at 2 weeks after second vaccination $(\mathrm{P}<0.05)$. All of the vaccinated groups showed a significant increase in antibody titration against preimmune and PBS groups.

\section{Cytokine assay results and Splenic Lymphocyte Proliferation Response}

The results of cytokine assay in groups of vaccinated chickens two weeks after the first vaccination and two weeks after boost vaccination and shown as the concentration of IFNa and IFNy shown in table 1. In this study, the concentration of IFN-gamma in IVT (Irradiated Vaccine plus Trehalose) intranasal group two weeks after the first vaccination was increased significantly and other groups at 2 weeks after the first vaccination were not increased for this item. Also 2 weeks after the second vaccination, concentration of IFN-gamma in IV (Irradiated Vaccine)-IN, IV-SC, IVT (Irradiated Vaccine plus Trehalose)-IN, IVT-SC and IVS (Irradiated Vaccine plus ISA70) groups were increased significantly $(p<0.05)$. Therefore, the most concentration of IFNgamma was shown in IVT two weeks after boost immunization intranasal and subcutaneously. Also, the concentration of IFN-gamma in the formalin vaccine is less than the irradiated vaccine by two routes of administration (IN and SC).

The concentration of IFN-alpha was increased in IVT.SC and FV groups two weeks after the first vaccination and in IV.SC group two weeks after the second vaccination significantly $(p<0.05)$.

According to the stimulation index there is a significant increase in IV and IVT groups 2 weeks after first vaccination (wafv) and 2 weeks after second vaccination (wasv) intranasal and subcutaneously $(p<0.05)$. Therefore, splenic Lymphocyte Proliferation was increased in IVT groups against other groups. So, splenic lymphocyte proliferation was increased up to the most stimulation index in IVT intranasal group 2 wasv.

Table1. The groups of vaccinated chicken and the concentration of IFNa and IFNy

\begin{tabular}{|c|c|c|c|c|c|c|}
\hline Vaccinated groups & $\begin{array}{l}\text { Rout of } \\
\text { Admins }\end{array}$ & $\begin{array}{l}\text { Time of } \\
\text { sampling }\end{array}$ & 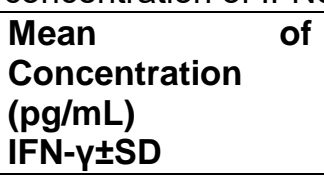 & $\begin{array}{l}\text { Mean of } \\
\text { Concentration } \\
(\mathrm{pg} / \mathrm{mL}) \\
\text { IFN- } \alpha \pm S D \\
\end{array}$ & $\begin{array}{l}\mathbf{A b} \\
\text { Titration } \pm S D\end{array}$ & SI士SD \\
\hline Preimmune & -- & & $30.17 \pm 1.49$ & $3.91 \pm 0.72$ & $1 \pm 0.81$ & $0.96 \pm 0.01$ \\
\hline PBS & IN & 2wafv & $19.56 \pm 2.78$ & $5.9 \pm 2.37$ & $0.5 \pm 0.57$ & $0.97 \pm 0.16$ \\
\hline IV & IN & 2wafv & $75.56 \pm 3.52$ & $18.21 \pm 4.6$ & $3 \pm 0.81$ & $1.32 \pm 0.71$ \\
\hline IV & SC & 2wafv & $47.01 \pm 16.73$ & $47.50 \pm 11.50$ & $2.5 \pm 0.7$ & $1.51 \pm 0.33$ \\
\hline IVT & IN & 2wafv & $188.65 \pm 24.05$ & $23.48 \pm 2.61$ & $3.37 \pm 0.47$ & $1.50 \pm 0.04$ \\
\hline IVT & SC & 2wafv & $78.19 \pm 19.10$ & $73.7 \pm 3.49$ & $2.5 \pm 0.40$ & $1.47 \pm 0.10$ \\
\hline FV & IN & 2wafv & $49.77 \pm 3.99$ & $88.77 \pm 27.38$ & $2.5 \pm 0.40$ & $0.45 \pm 0.20$ \\
\hline IVS & SC & 2wafv & $42.77 \pm 10.54$ & $54.61 \pm 9.98$ & $4.25 \pm 0.50$ & $1.03 \pm 0.05$ \\
\hline FVS & SC & 2wafv & $39.18 \pm 6.52$ & $10.54 \pm 0.76$ & $4 \pm 0.81$ & $0.99 \pm 0.04$ \\
\hline PBS & IN & 3wasv & $17.08 \pm 3.11$ & $3.91 \pm 1.71$ & $0.50 \pm 0.57$ & $0.97 \pm 0.09$ \\
\hline IV & IN & 3wasv & $268.37 \pm 11.73$ & $38.56 \pm 16.48$ & $3.37 \pm 0.95$ & $1.51 \pm 0.12$ \\
\hline IV & SC & 3wasv & $681.83 \pm 14.08$ & $70.41 \pm 23.26$ & $4 \pm 0.81$ & $1.58 \pm 0.11$ \\
\hline IVT & IN & 3wasv & $971.83 \pm 74.76$ & $44.65 \pm 5.06$ & $5 \pm 0.81$ & $1.65 \pm 0.07$ \\
\hline IVT & SC & 3wasv & $589.82 \pm 87.24$ & $38.86 \pm 2.40$ & $4.00 \pm 0.81$ & $1.28 \pm 0.07$ \\
\hline FV & IN & 3wasv & $63.20 \pm 15.91$ & $48.48 \pm 23.87$ & $3.37 \pm 0.47$ & $1.09 \pm 0.05$ \\
\hline IVS & SC & 3wasv & $243.06 \pm 29.71$ & $40.27 \pm 9.84$ & $4.50 \pm 0.57$ & $108 \pm 0.05$ \\
\hline FVS & SC & 3wasv & $76.64 \pm 30.36$ & $14.30 \pm 3.59$ & $5 \pm 0.81$ & $1.09 \pm 0.06$ \\
\hline
\end{tabular}

$\mathrm{BV}=$ before vaccination; $2 \mathrm{wafv}=$ Two weeks after first vaccination; 2 wasv= Two weeks after second vaccination; IV= Irradiated Vaccine; IVT= Irradiated Vaccine +Trehalose; IVS= Irradiated Vaccine+ISA70; FV= Formalin Vaccine; FVS= Formalin Vaccine+ISA70; SI= Stimulation Index for splenic lymphocyte proliferation 


\section{Histopathology observation}

The histopathology results in the negative control group (PBS) were very small foci of congestion in the parenchyma and pulmonary sub epithelium as well as multiple foci of hemorrhage in the airway, perivenular edema (Figure 1A). Microscopic findings didn't vary from mild to severe in the trial groups. In the intranasal vaccination, slides were shown lymphocyte infiltration (++), foci dispersed of hemorrhage and edema (Figure 1B, Figure 1C) but in the injection vaccination (Figure 1D, Figure 1E), had intranasal vaccination symptoms addition to thickening of alveolar septa.

Table 2. The groups of vaccinated chicken and the histopathology observation

\begin{tabular}{|c|c|c|c|c|c|}
\hline No & groups & $\begin{array}{l}\text { Rout of } \\
\text { Adminstration }\end{array}$ & $\begin{array}{l}\text { Dose of } \\
\text { vaccine }\end{array}$ & $\begin{array}{l}\text { Date of } \\
\text { sampling }\end{array}$ & Histopathological findings \\
\hline 1 & PBS & IN & 1 & 2wafv & $\begin{array}{l}\text { Scattered very small blood foci of congestion in } \\
\text { parenchyma and pulmonary sub epithelium as well as } \\
\text { multiple foci of hemorrhage in the air way, perivenular } \\
\text { edema }\end{array}$ \\
\hline 2 & IV & IN & 1 & 2wafv & $\begin{array}{l}\text { thickening of alveolar septa, multiple foci dispersed of } \\
\text { hemorrhage, pulmonary edema in air spaces, } \\
\text { Lymphocytic infiltration (+) }\end{array}$ \\
\hline 3 & IVT & IN & 1 & 2wafv & $\begin{array}{l}\text { Multiple foci dispersed of hemorrhage, edema and } \\
\text { hemorrhage, Mild lymphocyte infiltration in para } \\
\text { bronchial }(+) \text {, desquamation of epithelium in air way, } \\
\text { Severe thickening of alveolar septa }\end{array}$ \\
\hline 4 & FV & IN & 1 & 2wafv & $\begin{array}{l}\text { Mild lymphocyte infiltration (+) in para bronchial, small } \\
\text { foci of edema and hemorrhage }\end{array}$ \\
\hline 5 & IVS & SC & 1 & 2wafv & Mild thickening of alveolar septa \\
\hline 6 & FVS & SC & 1 & 2wafv & Moderate thickening of alveolar septa \\
\hline 7 & PBS & IN & 2 & 3wasv & $\begin{array}{l}\text { Scattered very small foci of congestion in parenchyma, } \\
\text { pulmonary sub-epithelium as well as multiple foci of } \\
\text { hemorrhage in the air way, perivenular edema }\end{array}$ \\
\hline 8 & IV & IN & 2 & 3wasv & $\begin{array}{l}\text { Mild lymphocyte infiltration (+), thickening of alveolar } \\
\text { septa, extensive foci of hemorrhage and congestion. }\end{array}$ \\
\hline 9 & IVT & IN & 2 & 3wasv & $\begin{array}{l}\text { Mild lymphocyte infiltration }(+) \text {, thickening of alveolar } \\
\text { septa, extensive foci of hemorrhage and congestion } \\
\text { and edema }\end{array}$ \\
\hline 10 & FV & IN & 2 & 3wasv & Moderate thickening of alveolar septa \\
\hline 11 & IVS & SC & 2 & 3wasv $n$ & $\begin{array}{l}\text { Lymphocytic infiltration (+) in forming foci and limited, } \\
\text { Mild thickening of alveolar septa }\end{array}$ \\
\hline 12 & FVS & SC & 2 & 3wasv & $\begin{array}{l}\text { Lymphocytic infiltration (+) and foci dispersed of } \\
\text { hemorrhage }\end{array}$ \\
\hline
\end{tabular}

2wafv= Two weeks after first vaccination; 3wasv= Three weeks after second vaccination; IV= Irradiated Vaccine; IVT= Irradiated Vaccine +Trehalose; IVS= Irradiated Vaccine+ISA70; FV= Formalin Vaccine; FVS= Formalin Vaccine+ISA70 

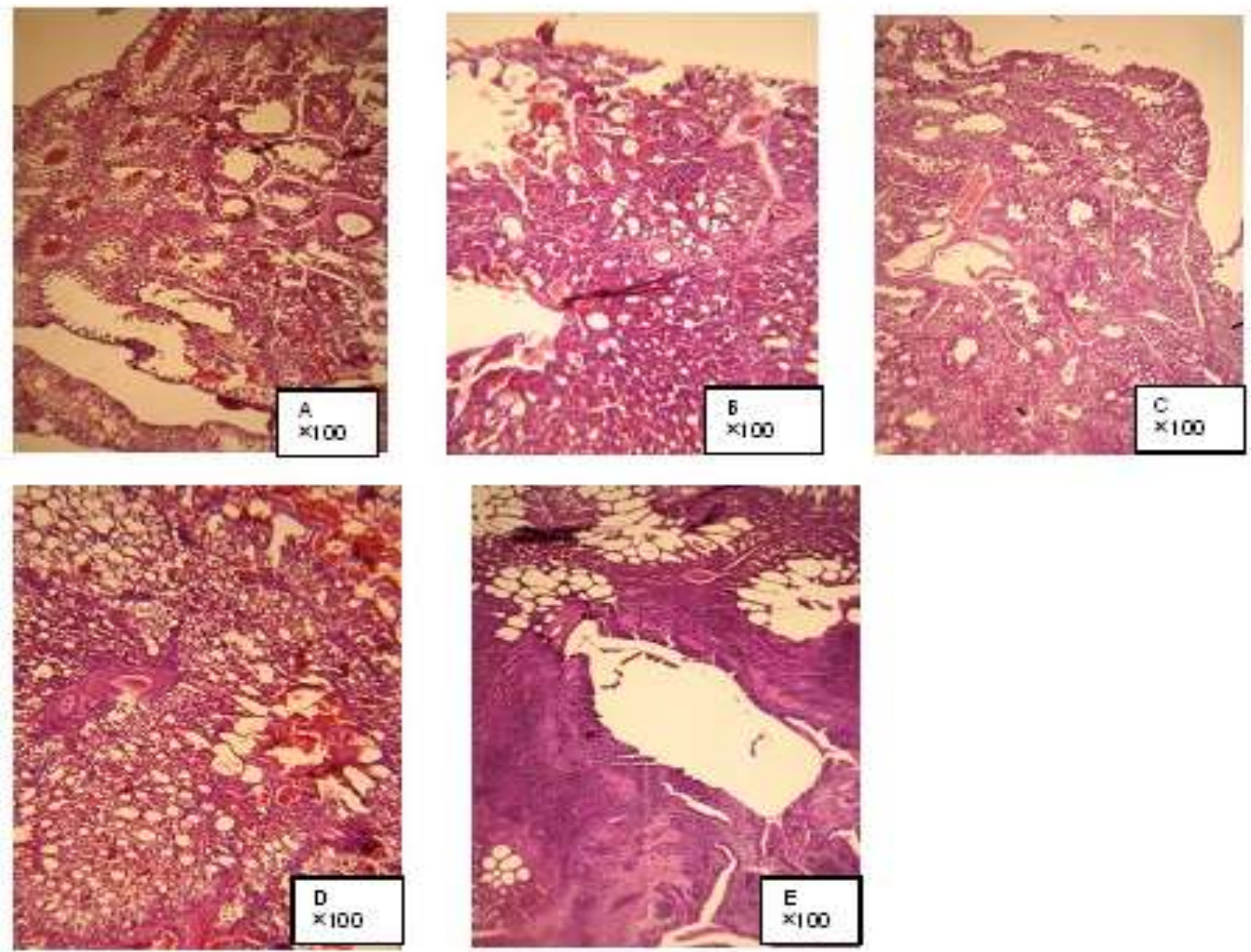

Figure 1. The histopathology results for the negative control group $(A)$, intranasal vaccination with the irradiated vaccine (B), intranasal vaccination with irradiated vaccine plus Trehalose (C), subcutaneously vaccination of irradiated vaccine (D), subcutaneously vaccination of formalin plus ISA70

\section{DISCUSSION}

The Avian influenza virus causes a viral disease in many bird species and also one of the instances of human health risks because it can create disease in humans by contact with infected poultry or its meats. Avian Influenza sub types H5, H7 and H9 are the most important zoonotic viruses. The H9N2 virus has low pathogenicity in birds but it is a serious threat to public health and prevailing vaccines decline the incidence of disease in birds, they can't completely prevent infection and not capable of preventing the shedding of the AIV. Vasfi indicated H9N2 virus can't induce viremia in infected poultry and suggested that strengthening conditions and simultaneous viral and bacterial infections influenced sever mortality (to $80 \%$ ) and egg fall (to $75 \%$ ) in the respiratory outbreak [1]. It is necessary to develop safer vaccines enable of providing protection against Influenza viruses. In this study was calculated gamma ray dose $30 \mathrm{kGy}$ for complete inactivation of the frozen AIV sub type H9N2 because it has been reported that frozen material during irradiation decreases free radical formation and accordingly barely the indirect damage to proteins. Shannon and coauthors used $50 \mathrm{kGy}$; their data showed the immunogenicity of highly pathogenic influenza virus irradiated at 50 kGy to induce higher antibody titration and cell-mediated immune responses and our data indicated that we could preserve maintained protein biological activity and high immune responses after exposure to $30 \mathrm{kGy}$ [6].

Furuya explained gamma-irradiated, Y-APC [A/Port Chalmers/1/73(H3N2)], has major immunogenicity and its protection was $100 \%$, a lower weight loss in mice who vaccinated with formalin or UV inactivated vaccines [29]. Their data indicated $y$-ray inactivated virus induced immunity with high quantitatively and qualitatively to the inactivated virus by formalin or UV-irradiation [30]. Also, they reported $\mathrm{Y}$-A/PC-vaccinated mice had reduced lung inflammation and reduced lung viral loads [24]. He indicated that disinfection by $\mathrm{Y}$-ray is very capable than the other vaccine preparation methods, in providing immunogenicity of the influenza virus and infusion of cross- protective immunity [30].

Thomas showed poly I:C as adjuvant can increase both humoral and cellular immune responses, IFNy, IFNa, IL-2 cytokines production in mice and reduce AIV replication and shedding in poultry and control H9N2 
IV in ducks [31]. In our study, after the first intranasal vaccination, the amount of the IFN-gamma was increased to different levels in the samples of the irradiated vaccine with Trehalose compared to other vaccine groups. It indicates that Trehalose had a positive effect on cytokines production and enhanced the IFNy level in poultry. In the second intranasal vaccination, compared to the first vaccination level of IFNy was significantly increased $(\mathrm{P}<0.05)$. In this study, we showed IFNy concentration in an intranasal routes were more than an injection way. One of the opinion for the reason to increase IFN- $\gamma$, antibody titration and lymphocyte proliferation in the IVT-intranasal group is that Trehalose not only is as a protectant for viral protein during freezing of irradiated viral stock at $-70^{\circ} \mathrm{C}$ [32], but also it makes more viscosity in the vaccine solution. Therefore, when a drop of vaccine puts into the bird's nose and the most of the time, the bird shakes its head and it makes a portion of the drop throw out, however, the vaccine solution with Trehalose is used, by head shaking it doesn't throw out because of the more viscous solution.

Motamedi-Sedeh showed that radiation can keep the antigenic characteristic of inactivated virus antigen and thus it is a good way for the immunization of animals to induce neutralizing antibody titers and cytokine concentration such as IL-2 and IFNy [33]. Meng explains IFN- $\alpha$ can to protect chickens against AIV [34]. In this study most of the vaccinated groups haven't shown any increase in IFN- $\alpha$ concentration, only the peak IFN- $\alpha$ level was shown in the formalin vaccine group. As we know IFN- $\alpha$ production after virus infection is transit, fast and nonspecific and after about 10 hours it disappeared. Therefore, after two weeks it was disappeared.

Dong-hun Lee demonstrated that the use of the VLP vaccine would help in restricting the safety effects compared to live-attenuated and inactivated whole virus vaccines and because absences of viral antigenic materials have a high safety will be a good vaccine candidate in a feature. They depicted ISA70 is a safe and impressive adjuvant in many poultry diseases and VLP with the ISA70 induce high titers of antibody compare with VLP without adjuvant [8]. Our results indicated that ISA70 induce a high titer in INFY. But when we used of Trehalose, IFNy titer had more increasing, therefore the magnitude of protection was in the irradiated with Trehalose vaccine group.

Gauger reported live attenuated flu vaccines with genetic modifications have steady cross-protection and decrease in shedding compared whole inactivated virus (WIV) vaccines. They demonstrated live attenuated influenza vaccines (LAIV) reduce clinical and lung lesions compared to WIV vaccine and unvaccinated animals, also was decreased Pneumonia in the LAIV-IN and WIV-IN pigs [35]. In our study suggested that ulcers in injection vaccine groups were lower than intranasal vaccine groups. We observed lymphocytic infiltration (+) in forming foci and limited, mild thickening of alveolar septa in injection vaccines but we have thickening of alveolar septa, multiple foci dispersed of hemorrhage, pulmonary edema in air spaces and Lymphocytic infiltration in intranasal vaccines. What are important, the enhanced respiratory lesions were observed in irradiated vaccine plus Trehalose in intranasal and the lowest lesions in irradiated with ISA70 in SC vaccines. The results of this study show critical advantages to the use of irradiated vaccines with Trehalose in poultry populations.

Nakayama showed formalin-inactivated whole virus particles vaccines by nasal vaccination could induce antigen-specific $\operatorname{lgE}$ secretion and eosinophilic infiltration and suggested not only mucosal and serum $\lg A$ but also blood IgG of B cells. They explained flu vaccine-specific IgE have a protective role but it can cause an increase in the appearance of allergy because of the gathering of antigen specific $\lg \mathrm{E}$ in the nasal mucosa. However they did not detect any anaphylaxis or allergic symptoms in their samples [10]. In addition, we showed FV intranasal can induce antibody titration and IFN-y concentration.

\section{CONCLUSION}

Finally this research showed irradiated AIV sub type H9N2 can be a good candidate for vaccine preparation, and Trehalose as a disaccharide makes more viscosity in vaccine solution so, it makes more absorbance of antigen by the inhalation route.

Funding: This research was funded by the Department of Nuclear Sciences and Applications, Animal Production and Health Section, International Atomic Energy Agency (IAEA), VIC, Vienna, Austria, grant number; (IAEA Coordinated Research Project, CRP No. 22126).

Acknowledgments: The authors express their gratitude to Dr. Iraj Khalili from Razi Vaccine and Serum Research Institute of Iran. We express our gratitude to the Department of Nuclear Sciences and Applications, Animal Production and Health Section, International Atomic Energy Agency (IAEA), VIC, Vienna, Austria for supporting (IAEA Coordinated Research Project, CRP No. 22126). Especially the authors gratitude to Dr. Hermann Unger.

Conflicts of Interest: The authors declare no conflict of interest. The funders had no role in the design of the study; in the collection, analyses, or interpretation of data; in the writing of the manuscript, or in the decision to publish the results". 


\section{REFERENCES}

1. Vasfi-Marandi M, BozorgmehriFard MH. Isolation of H9N2 subtypes of avian influenza viruses during an outbreak in chickens in Iran. Iran Biomed J. 2010; 6(1): 13-7.

2. Webster RG, Kawaoka Y. Avian influenza. Crit Rev Poult Biol. 1988; 1: 211-46.

3. Alexander DJ. The epidemiology and control of avian influenza and Newcastle disease. J Comp Patho. 1995; 112(2): 105-26. https://doi.org/10.1016/S0021-9975(05)80054-4.

4. Cauthen AN, Swayne DE, Sekellick MJ, Marcus PI, Suarez DL. Amelioration of influenza virus pathogenesis in chickens attributed to the enhanced interferon- inducing capacity of a virus with a truncated NS1 gene. J Virol. 2007; 81(4): 1838-47. https://doi.org/10.1128/JVI.01667-06.

5. Khalil AA, Hussein HA, Tolba SK, El-Sanousil AA. Preparation and evaluation of H9N2 vaccine adjuvant with montanide ISA71 VG. Glob Veter. 2015; 14(5): 670-4. https://doi.org/10.5829/idosi.gv.2015.14.05.94190.

6. David SC, Lau J, Singleton E, Babb R, Davies J, Alsharifi M, et al. The effect of gamma-irradiation conditions on the immunogenicity of whole-inactivated influenza A virus vaccine. Vaccine. 2017; 35: 1071-9. https://doi.org/10.1016/j.vaccine.2016.12.044.

7. Pushko P, Tretykova I, Hidajat R, ZSAK A, Chrzastek K, Tumpey TM, et al. Virus- like particles displaying H5, H7, $\mathrm{H} 9$ hemagglutinins and $\mathrm{N} 1$ neuraminidase elicit protective immunity to heterologous avian influenza viruses in chickens. Virolo. 2017; 501: 176-82. https://doi.org/10.1016/j.virol.2016.12.001.

8. Lee D, Park J, Lee Y, Song J, Kang S, Lee J, et al. H9N2 avian influenza virus-like particle vaccine provides protective immunity and a strategy for the differentiation of infected from vaccinated animals. Vacci. 2011; 29: 40037. https://doi.org/10.1016/j.vaccine.2011.03.067.

9. Peacock TP, James J, Sealy JE, Iqbal M. A Global Perspective on H9N2 Avian Influenza Virus. Viru. 2019, 11, 620. doi:10.3390/v11070620.

10. Nakayama M, Itoh Y, Shichinohe S, Nakabayashi R, Ishigaki H, Sakoda Y, et al. Potential risk of repeated nasal vaccination that induces allergic reaction with mucosal $\mathrm{lgE}$ and airway eosinophilic infiltration in cynomologus macaques infected with H5N1 highly pathogenic avian influenza virus. Vacci. 2017;35:100817.https://doi.org/10.1016/j.vaccine.2017.01.008.

11. Zhang A, Lai H, Xu J, Huang W, Liu Y, Zhao D, Chen R. Evaluation of the protective efficacy of poly I: C as an adjuvant for H9N2 subtype avian influenza inactivated vaccine and its mechanism of action in ducks. J. pone. 2017; 0170681. https://doi.org/10.1371/journal.pone.0170681.

12. Furuya $Y$, Regner M, Lobigs M, Koskinen A, Mullbacher A, Alsharifi M. Effect of inactivation method on the crossprotective immunity induced by whole killed influenza A viruses and commercial vaccine preparation. J. Gen. Virol. 2010; 91: 1450-60. https://doi.org/10.1099/vir.0.018168-0.

13. Alsharifi M, Furuya $Y$, Bowden TR, Lobigs M, Koskinen A, Regner M, et al. Intranasal flu vaccine protective against seasonal and H5N1 avian influenza infection. Plos One. 2009; 4 (4): e5336 https://doi.org/10.1371/journal.pone.0005336.

14. OIE. Terrestrial Manual: Manual of Diagnostic Tests and Vaccines for Terrestrial Animals. Avian influenza. Infection with avian influenza virus. World Organization for Animal Health, Chapter 2018; 3.3.4:1. http://www.oie.int/fileadmin/Home/eng/Health_standards/tahm/3.03.04_Al.pdf.

15. Hume AJ, Ames J, Rennick LJ, et al. Inactivation of RNA Viruses by Gämma Irradiation. Viru 2016; 8: $204-212$.

16. Wang W, Yu Z, Su W. Ion Irradiation and Biomolecular Radiation Damage II. Indirect Effect. Cornell University: 2010, arXiv: 1004.4394 [physics.bio-ph].

17. Lomax ME, Folkes LK, O’Neill P. Biological consequences of radiation-induced DNA damage: Relevance to radiotherapy. Clin Oncolo. 2013; 25: 578-85.

18. Ohshima $\mathrm{H}$, lida $\mathrm{Y}$, Matsuda A, Kuwabara M. Damage induced by hydroxyl radicals generated in the hydration layer of gamma-irradiated frozen aqueous solution of DNA. J Radia Rese. 1996; 37: 199-207.

19. Summers WC, Szybalski W. Gamma-irradiation of deoxyribonucleic acid in dilute solutions. II. Molecular mechanisms responsible for inactivation of phage, its transfecting DNA, and of bacterial transforming activity. $J$ Molec Biolo. 1967; 26: 227-35.

20. Salehi B, Motamedi-Sadeh F, Madadgar O, et al. Analysis of antigen conservation and inactivation of gammairradiated avian influenza virus subtype H9N2. Acta Micro Immuno Hung. 2018; 1: 65(2), $163-71$. https://doi.org/10.1556/030.65.2018.025.

21. Reed LJ, Muench H. A simple method of estimating fifty percent endpoint, Am J Hyg. 1988; 27: 493-7. https://doi.org/10.1093/oxfordjournals.aje.a118408.

22. Ross (An Aviagen Brand) 308 Parent Stocks: Performance Objectives. Ross Parent Stock Management Handbook, 2016. http://eu.aviagen.com/assets/Tech_Center/Ross_PS//308SF-PS-EU-PO-EN-16.pdf

23. RaieJadidi B, Erfan-Niya H, Ameghi A. Optimizing the process of inactivating influenza virus subtype H9N2 by formalin in the production of killed avian influenza vaccine. Archi Razi Insti. 2017; 72(1): 43-9. https://doi.org/10.22034/ARI.2016.107486.

24. Astill J, Alkie T, Yitbarek A, et al. Induction of immune response in chickens primed in ovo with an inactivated H9N2 avian infuenza virus vaccine. BMC Res Notes. 2018; 11: 428. . https://doi.org/10.1186/s13104-018-3537-9.

25. Hablolvarid MH, SohrabyHaghdost I, Pourbakhsh SA, Gholami MR. Histopathological Study of Intratracheally Inoculated A/Chicken/Iran/259/1998 (H9N2) Influenza Virus in Chicken. Archi Razi. Insti. 2004; 58: 1, 51-62. https://doi.org/10.22092/ARI.2004.103825. 
26. Bancroft DJ, Suvarna SK, Layton C. Bancroft's Theory and Practice of Histological Techniques: Expert. Consult: Online and Print, [seventh Ed.]. Churchill Livingstone. 2014. https://www.elsevier.com/books/bancrofts-theory-andpractice-of-histological-techniques/unknown/978-0-7020-6886-7.

27. Abdel Hamid HS, Ellakany HF, Hussien HA, El-Bestaw AR, Abdel Baky KM. Pathogenicity of an Avian Influenza H9N2 Virus isolated From Broiler Chickens in Egypt. Alex J Vete Sci. 2016; 51(2): 90-100. https://doi.org/10.5455/ajvs.236275.

28. Ebrahimi SM, Nili H, Sohrabi N. Histopathological Evaluation of A/chicken/iran/339/02 (H9N2), an Iranian Field Isolate of Influenza Virus, on Japanese Quail (Coturnixcoturnix japonica). Wor Appl Sci J. 2010; 9 (2): 226-229.

29. Furuya $Y$, Chan J, Regner M, et al. Cytotoxic T cells are the predominant players providing cross-protective immunity induced by $\mathrm{Y}$-irradiated influenza A viruses. J virol. 2010; 84: 4212-4221. https://doi.org/10.1128/JVI.02508-09.

30. Furuya Y, Chan J, Wan E, Koskinen A, Diener KR, Hayball JD, et al. Gamma- irradiated influenza virus uniquely induces IFN-I mediated lymphocyte activation independent of the TL. R7/MyD88 pathway. Plos. 2011; 1(6): e25765. https://doi.org/10.1371/journal.pone.0025765.

31. Thomas M, Wang Z, Sreenivasan CC, et al. Poly I: C adjuvanted inactivated swine influenza vaccine induces heterologous protective immunity in pigs. Vacci. 2015; 33: 542-548. https://doi.org/10.1016/j.vaccine.2014.11.034.

32. Pastorino B Baronti C, Gould EA, Charrel RN, Lamballerie X. Effect of Chemical Stabilizers on the Thermostability and Infectivity of a Representative Panel of Freeze Dried Viruses. PLOS ONE. April 29, 2015. doi:10.1371/journal.pone.0118963.

33. Motamedi-sedeh F, Soleimanjahi H, Jalilian AR, et al. Development of protective immunity against inactivated iranian isolated of Foot-and-Mouth disease virus type O/IRN/2007 using gamma ray irradiated vaccine on Balb/c mice and guinea pigs. Interviro. 2015; 58: 190-196. https://doi.org/10.1159/000433538.

34. Meng M, Yang L, Xu C, et al. Recombination chicken interferon- $\alpha$ inhibits H9N2 avian influenza virus replication in vivo by oral administration. J inerf Cytok Res. 2011; 31: 533-538. https://doi.org/10.1089/jir.2010.0123.

35. Gauger PC, Loving CL, Khurana S, Lorusso A, Perez DR, Kehrli MJ, et al. Live attenuated influenza A virus vaccine protects against $A(\mathrm{H} 1 \mathrm{~N} 1)$ pdm09 heterologous challenge without vaccine associated enhanced respiratory disease. Virolo. 2014; 93-104. https://doi.org/10.1016.

2020 by the authors. Submitted for possible open access publication under the terms and conditions of the Creative Commons Attribution (CC BY NC) license (https://creativecommons.org/licenses/by-nc/4.0/). 